\title{
Cyclobenzoin Esters as Hosts for Thin Guests
}

\author{
Corie M. McHale, ${ }^{[a]}$ Lucas J. Karas, ${ }^{[a]}$ Xiqu Wang, ${ }^{[a]}$ Judy I. Wu, ${ }^{[a]}$ and Ognjen Š. Miljanić ${ }^{\star[a]}$
}

[a] Dr. C. M. McHale, L. J. Karas, Dr. X. Wang, Prof. J. I. Wu, Prof. O. Š. Miljanić

Department of Chemistry

University of Houston

3585 Cullen Boulevard \#112, Houston TX 77204-5003, United States

E-mail: miljanic@uh.edu

Supporting information for this article is given via a link at the end of the document. Crystal data for co-crystals $\mathbf{1 a} \cdot \mathbf{2}, \mathbf{1 a} \cdot \mathbf{3}, \mathbf{1 a} \cdot \mathbf{4}, \mathbf{1 a} \cdot \mathbf{5}, \mathbf{1 b} \cdot \mathbf{6}_{2}, \mathbf{1 c} \cdot \mathbf{6}{ }_{2}$, and 1c. 7 has been deposited with the Cambridge Crystallographic Data Centre, under deposition codes 2054569-2054575.

\begin{abstract}
Nitriles and terminal alkynes are important compounds in industrial and academic settings. Their supramolecular binding has been challenging without the intervention of metals, because of the small dimensions of their linear $-\mathrm{C} \equiv \mathrm{N}$ and $-\mathrm{C} \equiv \mathrm{CH}$ groups. Using a combination of crystallography and computation, we have shown that cyclotetrabenzoin esters can host terminal triple bonds of alkynes and nitriles in their electron-poor cavities. Within these cavities, $\pi$-clouds of triple bonds can establish favorable and virtually equidistant interactions with the four aromatic walls of the cyclotetrabenzoin skeleton. Binding is selective for aliphatic nitriles and terminal alkynes, with their aromatic counterparts residing outside of the cyclotetrabenzoin cavity. These findings are of relevance in the binding, separations, and activation of these and other linear molecular guests.
\end{abstract}

Triple bonds of terminal alkynes and organic nitriles occupy a special place in organic chemistry. Their sp-hybridization makes them linear, short, sterically undemanding, and acidic in the case of alkynes. ${ }^{1}$ At the same time, the remaining p-orbitals offer reactivity which ranges from electrophilic to nucleophilic, both in uncatalyzed and metal-catalyzed reactions. Recently, terminal alkynes have been undergoing a veritable renaissance of interest as medicinal chemistry motifs, ${ }^{2}$ synthons for the preparation of oligoyne rotaxanes ${ }^{3}$ and other mechanically interlocked molecues, ${ }^{4}$ new allotropes of carbon, ${ }^{5}$ and precursors in the now-ubiquitous Cu-catalyzed azide-alkyne cycloaddition (click reaction). ${ }^{6}$ Nitriles remain hugely important as polymerization precursors ${ }^{7}$ and as functional motifs in medicinal chemistry. ${ }^{8}$

Given the large relevance of nitriles and terminal alkynes in these many contexts, their supramolecular chemistry had been surprisingly underexplored. Receptors developed for these two classes of molecules relied chiefly on the coordination of the nitrogen's lone pair in nitriles ${ }^{9}$ or the engagement of the terminal hydrogen in alkynes either via deprotonation ${ }^{10}$ or $[\mathrm{C}-\mathrm{H} \cdots \pi]$ interactions. ${ }^{11}$ However, the recognition of the triple bond itself as a motif for noncovalent interactions has little precedent. Nitriles have been included into the cavities of brominated calixarenes, ${ }^{12}$ Klemperer's inorganic cavitand, ${ }^{13}$ and a Mg-based MOF; ${ }^{14}$ their recognition by pillarenes was utilized to construct supramolecular polymers. ${ }^{15}$ Terminal alkynes were found to form complexes with urea as early as $1960,{ }^{16}$ and have been included into the cavities of Rebek's capsules ${ }^{17}$ and V-shaped adamantane-based hosts. ${ }^{18}$ In most cases, however, crystal structures were not obtained, nor was significant selectivity observed. In this Communication, we show that the readily synthesized cyclotetrabenzoin esters can serve as hosts for thin aliphatic nitrile and terminal alkyne guests, which engage their m-bonds through interactions with the four aromatic walls of the host cavity.

Cyclotetrabenzoin esters ${ }^{19}$ 1a-c (Figure 1) can be prepared on a gram scale by acylation of cyclotetrabenzoin. ${ }^{20}$ Crystal structures of $\mathbf{1 a}$ and $\mathbf{1 c}$ exhibited both intrinsic and extrinsic pores, while that of $\mathbf{1 b}$ showed no discernible pores. Compound 1a was found to be permanently porous upon solvent removal, with a Brunauer-Emmett-Teller (BET) surface area of $572 \pm 16 \mathrm{~m}^{2} \mathrm{~g}^{-1}$

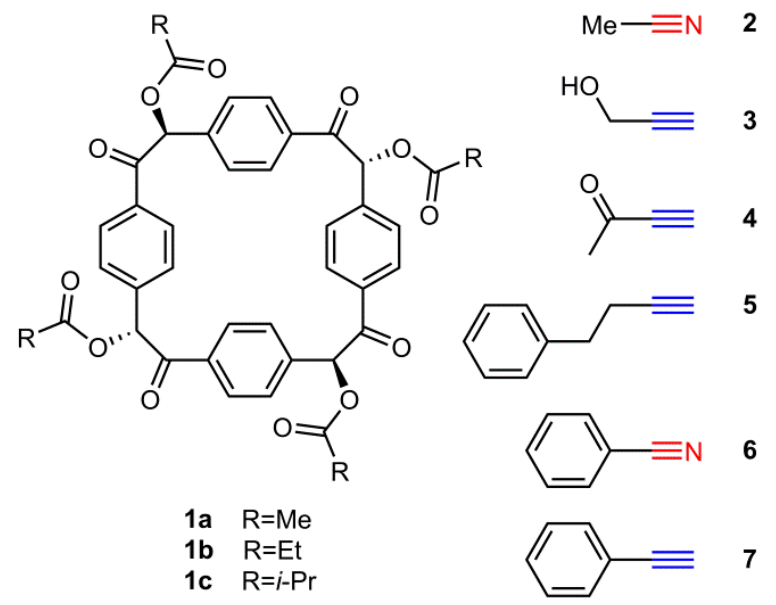

Figure 1. Cyclotetrabenzoin esters $\mathbf{1 a - c}$ and nitrile (2 and $\mathbf{6})$ and terminal alkyne (3-5 and 7) guests used in this study.

During the crystallization of $1 \mathbf{c}$ from $\mathrm{CS}_{2}$, we found that this linear solvent molecule was included in the central cavity of the cyclotetrabenzoin host, in an arrangement which resembled an insulated wire. This finding suggested that $1 \mathbf{1 a}-\mathbf{c}$ could act as supramolecular hosts for other guests that are thin enough to fit into their cavities, or for linear components of more complex molecules. To test this hypothesis, we crystallized 1a from acetonitrile (2) as the solvent. To our delight, the single crystal structure of complex 1a.2 (Figure 2, top left) showed the triple bond of $\mathbf{2}$ included in the cavity of $\mathbf{1 a}$. Molecules of $\mathbf{2}$ are disordered over four orientations: one pair of positions has the $\mathrm{C} \equiv \mathrm{N}$ bond inserted in the cavity of $1 \mathbf{a}$ from the "top" and the other one from the "bottom" (only one of these orientations is shown in Figure 2). Within each pair, two different orientations of the Me group are observed, rotated by $60^{\circ}$ relative to each other around the axis of the $\mathrm{C} \equiv \mathrm{N}$ bond. The centroid of each $\mathrm{C} \equiv \mathrm{N}$ bond is positioned $3.60 \AA$ away from the averaged planes of two aromatic rings on the opposite sides of $1 \mathbf{a}$, and $3.28 \AA$ away from the averaged planes of the other two aromatic rings of $\mathbf{1 a}$. These pairs of distances are very close to the idealized $3.40 \AA$ 
$[\pi \cdots \pi]$ stacking distance between aromatic rings. ${ }^{21}$ To evaluate how deeply the $\mathrm{C} \equiv \mathrm{N}$ bond is included in the cavity of $\mathbf{1 a}$, we measured the distance of its centroid from the average horizontal plane of $1 \mathbf{a}$, defined by the four $\mathrm{Ph}-\mathrm{C}=\mathrm{O}$ and four $\mathrm{Ph}-$ $\mathrm{CHOAc}$ bonds. The triple bond's centroid resides $1.20 \AA$ above this averaged plane.
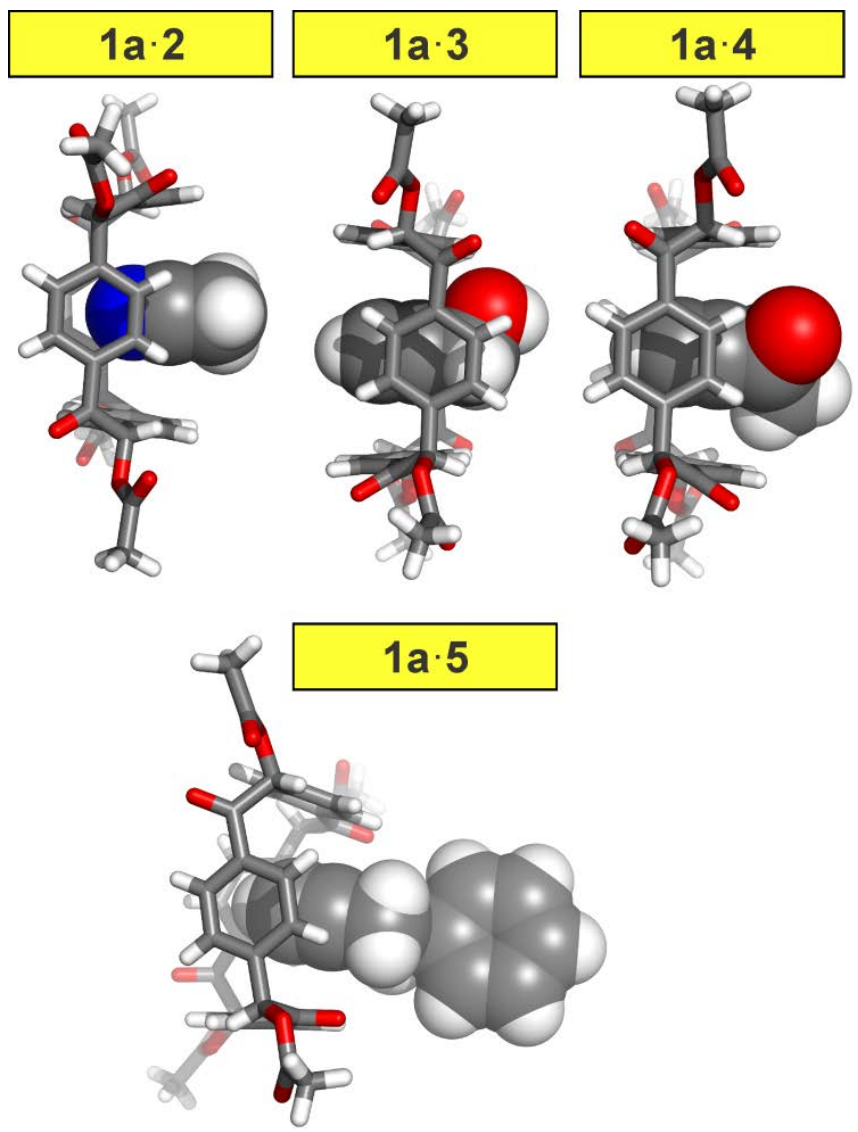

Figure 2. Crystal structure of complexes 1a.2, 1a.3, 1a.4, and 1a.5 all show the inclusion of their triple bonds into the central pore of 1a. In these complexes, the guest is disordered over four (2, 3, and 4) or two (5) orientations; only one of these orientations is shown. Element colours: Cgrey, $\mathrm{O}$-red, $\mathrm{N}$-blue, $\mathrm{H}$-white.

Several notable short contacts were observed in the extended packing diagram of $\mathbf{1 a} \cdot \mathbf{2}$. Two hydrogens of the Me group of 2 establish short (2.49 and $2.61 \AA$ ) contacts with the ester carbonyl oxygens of the two neighboring molecules of $\mathbf{1 a}$. Short $(2.79 \AA)$ contacts are also established between the hydrogens of the methyl group of one molecule of $1 \mathbf{a}$ and the ester carbonyl oxygens on another molecule of $\mathbf{1 a}$. These contacts repeat themselves on each of the four corners of $\mathbf{1 a}$, organizing the molecules into a square grid with molecules of 2 included into every other pore (Figure 3, top left). Neighboring sheets are rotated by $\pm 27.8^{\circ}$ (measured as the angle between planes of benzene rings in molecules of $\mathbf{1 a}$ in neighboring sheets) with respect to each other. Vertical alignment of these sheets involves no strong directional interactions. Noticeable are only $[\mathrm{C}-\mathrm{H} \cdots \mathrm{O}$ ] contacts between (a) ketone oxygen in one molecule and hydrogens on two aromatic rings in its neighbor (2.72 and $2.85 \AA$ ) , (b) ester carbonyl oxygen in one molecule and hydrogens on two aromatic rings in its neighbor (2.78 and $2.81 \AA$ ), and (c) ketone oxygen in one molecule and $\mathrm{AcOC}-\mathrm{H}$ hydrogen in its neighbor $(2.28 \AA)$.

Encouraged by this observation, we expanded our study to other guests with linear functional groups: aliphatic and aromatic terminal alkynes and nitriles. Co-crystals of cyclobenzoin esters were obtained with five additional guests 3-7, shown in Figure 1.

Three terminal alkynes were crystallized with macrocyclic host 1a: propargyl alcohol (3, Figure 2, top center), 3-butyne-2one (4, Figure 2, top right), and 4-phenyl-1-butyne (5, Figure 2, bottom). While crystallization of these guests was attempted with all three cyclotetrabenzoin esters $\mathbf{1 a}-\mathbf{c}$, only $\mathbf{1 a}$ produced $\mathrm{X}$-ray diffraction quality co-crystals. For all three guests, the terminal $\mathrm{C} \equiv \mathrm{C}-\mathrm{H}$ group was included in the center of the intrinsic pore of 1a. Just like in the case of $\mathbf{1 a} \cdot \mathbf{2}$, complexes of $\mathbf{1 a}$ with $\mathbf{3}$ and $\mathbf{4}$ show these two guests disordered around four positions. In contrast, the 4-phenyl-1-butyne (5) guest was disordered over two positions. The triple bonds of $\mathbf{3}$ and $\mathbf{4}$ are inserted deeper into 1a's cavity than was the case with $\mathbf{2}$ : the distances between the centroids of the $\mathrm{C} \equiv \mathrm{C}$ bonds and the average horizontal planes of $\mathbf{1 a}$ are $0.60 \AA$. In the $\mathbf{1 a} \cdot \mathbf{5}$ complex, this distance is slightly longer: $1.43 \AA$. Once again, the relative positioning of the aromatic walls of $\mathbf{1 a}$ and the guests' triple bonds is very suggestive of $[\pi \cdots \pi]$ stacking between these moieties. The distances between the centroids of the $\mathrm{C} \equiv \mathrm{C}$ bonds and the aromatic walls of $\mathbf{1 a}$ are 3.42 and $3.53 \AA$ in $\mathbf{1 a \cdot 3}, 3.45$ and 3.54 $\AA$ in $\mathbf{1 a} \cdot \mathbf{4}$, and 3.36 and $3.55 \AA$ in $\mathbf{1 a} \cdot \mathbf{5}$. The triple bonds fit perfectly within the cavity of $1 \mathbf{a}$, allowing virtually equidistant interactions with all four surrounding aromatic rings. Overall, guest $\mathbf{5}$ distorts the structure of $\mathbf{1 a}$ the most compared to the empty host, causing significant twisting between aromatic rings on the opposite sides of the macrocycle. Tentatively, this can be explained by the interactions that the phenyl ring of $\mathbf{5}$ establishes with structural elements of 1a positioned outside of the cavity. Namely, this phenyl ring finds itself sandwiched between two aromatic planes of two different molecules of 1a $\left(C^{A r}\right.$-centroid distances of $3.78 \AA$ ) and its hydrogen atoms establish short contacts $(2.70 \AA)$ with the $\mathrm{C}=\mathrm{O}$ group of the 1a's ester moiety.

As can be seen from Figure 3 , packing of $1 \mathrm{a}$ is essentially identical regardless of whether $\mathbf{2}, \mathbf{3}$, or $\mathbf{4}$ are included as guest molecules. These structures are also very much like the packing structure of $\mathbf{1 a}$ devoid of any guests. ${ }^{19}$ The molecules of $\mathbf{3}$ form two additional short contacts between their oxygen atoms and aromatic hydrogens of $1 \mathbf{a}(2.32$ and $2.61 \AA)$. The molecules of 4 form two short contacts with 1a within the same layer (a) between the ester carbonyl and hydrogen of methyl group of 3butyne-2-one $(2.78 \AA)$ and (b) between a hydrogen on the methyl group of 1a and the ketone oxygen of $4(2.97 \AA)$. 


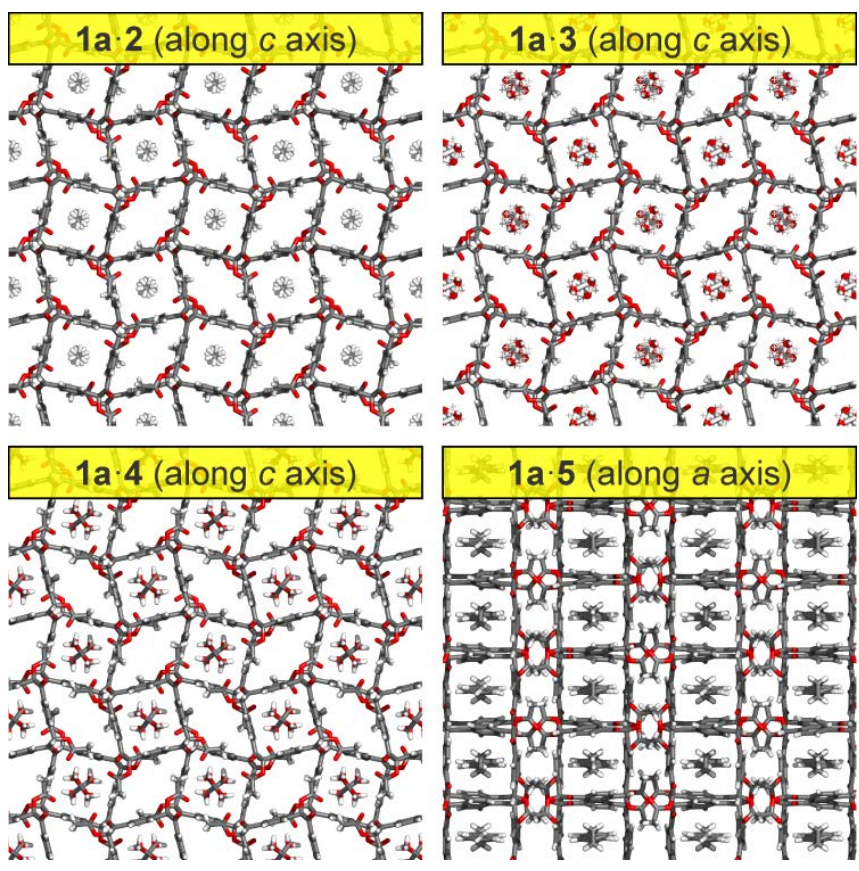

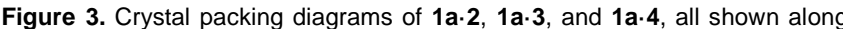
the crystallographic $c$ axis, highlight the virtually identical framework of host molecules 1a filled with different guests. The packing diagram of 1a.5 is quite different, and shown along the crystallographic a axis. Element colours: Cgrey, $\mathrm{O}$-red, $\mathrm{N}$-blue, $\mathrm{H}$-white.

Guest 5 causes a significant change in this organization of its host, that is best appreciated when viewed down the crystallographic a axis (Figure 3 , bottom right). In this view, the square intrinsic pore of $\mathbf{1 a}$ is filled with molecules of 4-phenyl-1butyne pointing their alkyne triple bonds into the cavity of $\mathbf{1 a}$, while the ester groups form a narrow channel between macrocycles. Vertical sheets stack offset where the macrocycles are not directly on top of one another. These sheets are held together by a series of short contacts. Two-dimensional sheets are established through $[\mathrm{C}-\mathrm{H} \cdots \mathrm{O}]$ contacts between (a) ester carbonyl oxygen and AcOC-H hydrogen in its neighbor $(2.28 \AA)$ and (b) ester carbonyl oxygen of one molecule and the hydrogen of the methyl group on another molecule $(2.78 \AA)$. Neighboring sheets are connected by $[\mathrm{C}-\mathrm{H} \cdots \mathrm{O}]$ contacts between (a) ketone oxygen in one molecule and an aromatic hydrogen on its neighbor $(2.39,2.83$, and $2.92 \AA)$ and (b) ketone oxygen in one molecule and hydrogens on the methyl group of its neighbor $(2.58 \AA)$.

In contrast to the aliphatic guests 2-5, their aromatic counterparts 6 and 7 did not co-crystallize with 1a. However, switching to $\mathbf{1 b}$ and $\mathbf{1 c}$ as the hosts provided three co-crystals of sufficient quality for X-ray diffraction. Benzonitrile (6) cocrystallized with both $\mathbf{1 b}$ and $\mathbf{1 c}$, while phenylacetylene (7) formed crystals just with 1c. In all these co-crystal structures, the aromatic guests were found to reside outside of the cavity of $\mathbf{1 b} / \mathbf{1 c}$. In the crystal structure of $\mathbf{1 b} \cdot \mathbf{6}_{2}$ (Figure 4 , top left), two molecules of $\mathbf{6}$ are located on the outside of the central cavity of 1b, establishing $[\pi \cdots \pi]$ stacking interactions with the two aromatic walls on the opposite sides of $\mathbf{1 b}$. The distances between centroids of the benzene rings of 6 and the average planes of the two aromatic walls of $\mathbf{1 b}$ are 3.52 and $3.89 \AA$. This $[\pi \cdots \pi]$ stacking is extended through the slipped stacking of two molecules of 6 which are in an antiparallel arrangement with an interplanar distance of $3.47 \AA$. Short contacts are also observed between molecules of $\mathbf{1 b}$ and $\mathbf{6}$ : (a) ester carbonyl oxygen and two aromatic hydrogens of $6(2.58$ and $2.78 \AA$ ) and (b) ketone oxygen and two aromatic hydrogen of $6(2.45 \AA$ and $2.77 \AA$ ). There are also two $[\mathrm{C}-\mathrm{N} \cdots \mathrm{H}]$ contacts between the nitrile nitrogen and hydrogen atoms on two aromatic rings of $\mathbf{1 b}$ (2.51 and $2.71 \AA$ ). The ethyl groups of $\mathbf{1} \mathbf{b}$ are found to pack directly below the cyclobenzoin cavity, establishing short $[\mathrm{C}-\mathrm{H} \cdots \mathrm{C}]$ contacts with aromatic walls that range in length from 2.88 to $3.36 \AA$. Other contacts include $[\mathrm{C}-\mathrm{H} \cdots \mathrm{O}$ ] contacts between (a) ester's alkoxy oxygen and an aromatic hydrogen in $\mathbf{1 b}(2.90 \AA)$, (b) ketone oxygen and an aromatic hydrogen (2.61 $\AA$ ), and (c) ester carbonyl oxygen and an aromatic hydrogen (2.61 $\AA$ ).

Macrocycle 1c also crystallizes with benzonitrile, with the guest located outside of the intrinsic pore (Figure 4, center left) and engaging in $\left[\pi^{\cdots} \pi\right]$ stacking with the outside walls of $\mathbf{1 c}$ (centroid-plane distance of $3.54 \AA$ ). Here again, the molecules of 6 engage in slipped $[\pi \cdots \pi]$ stacking with each other, in an antiparallel arrangement and with an interplanar distance of 3.52 $\AA$. Multiple short contacts are formed between 1c and 6, including $[\mathrm{C}-\mathrm{N} \cdots \mathrm{H}]$ contacts between the nitrogen of the nitrile and both aromatic and aliphatic hydrogens of $\mathbf{1 c}$, as well as between aromatic hydrogens of $\mathbf{6}$ and carbonyl and ester oxygen atoms of 1c. Crystal packing results in no discernable pores (Figure 4, center right) due to the efficient packing from the ester group stacking in the cyclobenzoin cavity, establishing short $[\mathrm{C}-\mathrm{H} \cdots \mathrm{C}]$ contacts that range in length from 2.84 to $3.12 \AA$. Other contacts include $[\mathrm{C}-\mathrm{H} \cdots \mathrm{O}]$ contacts between (a) ketone oxygen and $\left(\mathrm{CH}_{3}\right)_{2} \mathrm{C}-\mathrm{H}$ hydrogen (intramolecular, $2.62 \AA$ ) and (b) ketone oxygen and two aromatic hydrogens on two aromatic rings ( 2.54 and $2.65 \AA$ ).

The last diffraction-quality crystal produced was of $\mathbf{1 c}$ with phenylacetylene (7) as the guest, where molecules of $\mathbf{7}$ were also located outside of the central pore (Figure 4, bottom left). Molecules of 1c pack in such a way that two different pores are visible when viewed along the crystallographic $c$ axis (Figure 4, bottom right), one square-shaped derived from the intrinsic pore of 1c, and a second oval-shaped one, formed between two molecules of 1c. The disordered molecules of 7 are located within these oval pores. Curiously, they do not engage in aromatic $[\pi \cdots \pi]$ stacking interactions with the outer walls of $\mathbf{1 c}$ but are instead organized into parallel planes with interplanar distances of $2.61 \AA$. The oval pores are held together by four short [C-H $\cdots$ O ] contacts between the ester carbonyl oxygen and the hydrogens of the $\mathrm{CH}_{3}$ group (2.87 and $3.10 \AA$ ). To create a two-dimensional motif, there are a series of short contacts between (a) ketone oxygen and two aromatic hydrogens (2.71 and $2.75 \AA$ ) and (b) ketone oxygen and AcOC-H hydrogen on its neighbor $(2.82 \AA)$. There are also contacts formed between ketone and ester carbonyl oxygens of $\mathbf{1 c}$ and aromatic hydrogens of 7 (2.49 and $3.00 \AA$, respectively) and the methyl hydrogens of $1 \mathbf{c}$ and an aromatic carbon of $7(2.80 \AA)$. 

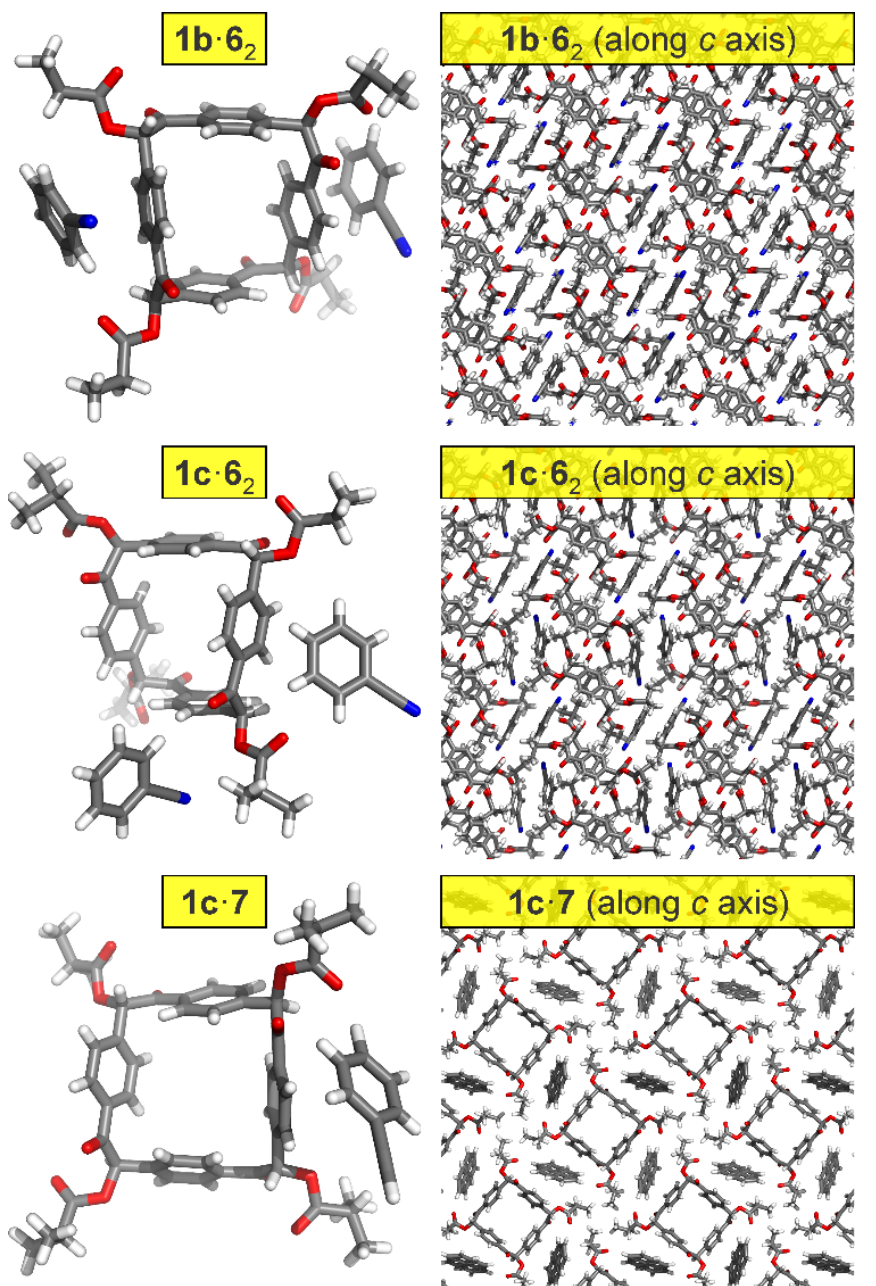

$1 c \cdot 6_{2}$ (along $c$ axis)
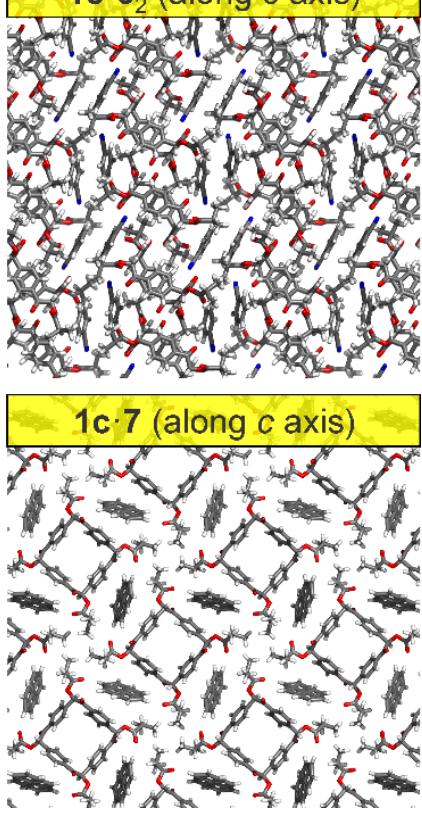

Figure 4. Crystal structures and backing diagrams of complexes $\mathbf{1 b} \cdot \mathbf{6}_{2}, \mathbf{1} \mathbf{c} \cdot \mathbf{6}_{2}$, and $\mathbf{1 c} \cdot \mathbf{7}$ show the guests outside of the cavity of hosts $\mathbf{1 b}$ and $\mathbf{1 c}$. This orientation allows the aromatic groups of the guests to stabilize by stacking interactions with benzene rings from multiple molecules of $\mathbf{1 b}$ or $\mathbf{1 c}$. Element colours: C-grey, $\mathrm{O}-$ red, $\mathrm{N}$-blue, $\mathrm{H}$-white.

To shed light on the energetics of guest inclusion in complexes of $\mathbf{1 a}$ with $\mathbf{2 - 5}$, we performed density functional theory (DFT) calculations. They revealed strong interaction energies $\left(\Delta E_{\text {int }}\right)$ of $-12.7 \mathrm{kcal} \mathrm{mol}^{-1}$ for $1 \mathrm{a} \cdot 2,-12.9 \mathrm{kcal} \mathrm{mol}^{-1}$ for 1a.3, $-14.5 \mathrm{kcal} \mathrm{mol}^{-1}$ for $\mathbf{1 a} \cdot \mathbf{4}$, and $-16.1 \mathrm{kcal} \mathrm{mol}^{-1}$ for $\mathbf{1 a} \cdot \mathbf{5}$. These $\Delta E_{\text {int }}$ values were computed based on the total electronic energy of the host-guest complex minus that of the isolated host and the isolated guest at the B3LYP-D3/6-31+G(d) level. Optimized geometries at the same level of theory show averaged distances $\left(d_{\text {avg }}\right)$ between the average planes of the four $\pi$-rings of $1 \mathbf{a}$ and the centroids of triple bonds of $\mathbf{2}$ ( $d_{\text {avg }}=$ $3.48 \AA), 3\left(d_{a v g}=3.50 \AA\right), 4\left(d_{a v g}=3.52 \AA\right)$, and $5\left(d_{a v g}=3.54 \AA\right)$, in good agreement with the crystallographically observed values. ${ }^{22}$ These calculated structures suggest an attraction between the guests and the cyclobenzoin host, which could be interpreted as favorable slipped-stack interactions of host's $\pi$ rings with either the $\pi$-clouds of the triple bonds, or with the acidic acetylenic $\mathrm{H}$ atoms in the cases of 3-5. The calculated stabilization energies are quite comparable to the those seen for the slip-stacked arrangement of the benzene dimer $(\sim 2.7 \mathrm{kcal}$ mol $^{-1}$ per interaction). ${ }^{23}$ Computed electrostatic potential maps of host 1a show that the guests interact with a fairly neutral interior of the host (green color, Figure 5), suggesting the importance of dispersion stabilizations in the host-guest interactions.

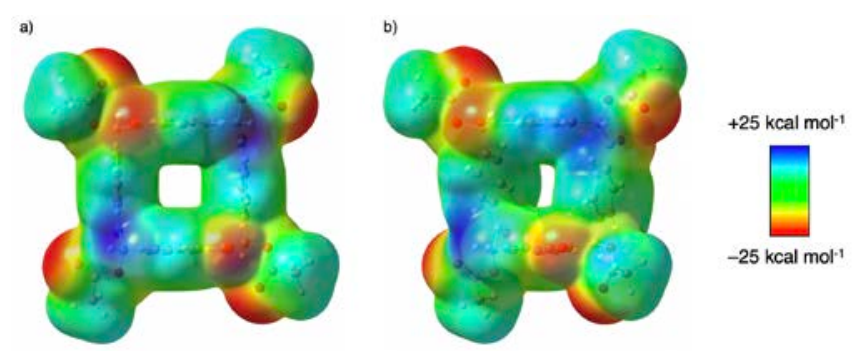

Figure 5. Computed electrostatic potential maps for the host 1a a) front view and b) side view on a 0.001 au contour surface. Blue color indicates positive potential and red color indicates negative potential.

In conclusion, we have crystallographically and computationally shown that the central pore of cyclobenzoins can be used to complex thin guests. Crystal growth of hostguest complexes showed that $\mathrm{C} \equiv \mathrm{N}$ and $\mathrm{C} \equiv \mathrm{C}-\mathrm{H}$ groups of aliphatic guests can enter the pores of $\mathbf{1 a - c}$, while those of aromatic guests cannot. This differentiation is tentatively a consequence of the competition of triple bonds and aromatic rings for $[\pi \cdots \pi]$ sites of hosts $\mathbf{1 a - c}$. Guests with sterically undemanding triple bonds are able to insert those functional groups into the cyclotetrabenzoin cavity. In contrast, guests with aromatic groups prefer to stabilize those moieties by interaction with aromatic rings from multiple molecules of $\mathbf{1 b} \mathbf{1} \mathbf{c}$; these interactions take place on the outside of the macrocycle cavity as aromatic rings cannot enter the pores of cyclotetrabenzoin. ${ }^{24}$

Our future work will focus on: (a) exploring other linear guests for inclusion into cyclotetrabenzoin cavities, with $\mathrm{CO}_{2}$ being the prime target, (b) modifying the electronic properties of $1 \mathbf{a}$ by substituting its aromatic rings in a way which would strengthen the association with nitrile and alkyne guests and allow the observation of their inclusion in the solution phase, and (c) exploration of guest binding properties of the recently prepared expanded cyclotetrabenzoins. ${ }^{25}$ The results of these studies will be reported in due course.

\section{Acknowledgements}

The authors acknowledge financial support from the donors of the American Chemical Society Petroleum Research Fund (grant ND-58919 to O.Š.M.), the Welch Foundation (grant E1768 to O.S.M.), the National Science Foundation (grants DMR1507664 to O.Š.M. and CHE-1751370 to J.I.W.), and the National Institute of General Medical Sciences of the National Institute of Health (grant R35GM133548 to J.I.W.). We acknowledge the use of the Sabine cluster and support from the Research Computing Data Core at the University of Houston.

\section{Keywords: cyclobenzoin • terminal alkyne • host-guest •} macrocycle $\bullet$ nitrile

[1] K. Karakida, T. Fukuyama, K. Kuchitsu, Bull. Chem. Soc. Jpn. 1974, 47 299-304.

[2] a) T. T. Talele, J. Med. Chem. 2020, 63, 5625-5663; b) C. Lenz, F, Boeckler, H, Hubner, P. Gmeiner, Bioorg. Med. Chem. 2005, 13, 4434-4442; c) C. Lenz, C. Haubmann, H. Hubner, F. Boeckler, P. Gmeiner, Bioorg. Med. Chem. 2005, 13, 185-191; d) 
[3] a) P. Gawel, S. Woltering, Y. Xiong, K. Christensen, H. L. Anderson, Angew. Chem. Int. Ed. 2020, doi: 10.1002/anie.202013623; b) S. L. Woltering, P. Gawel, K. E. Christensen, A. L. Thompson, H. L. Anderson, J. Am. Chem. Soc. 2020, 142, 13523-13532; c) L. D. Movsisyan, M. Franz, F. Hampel, A. L. Thompson, R. R. Tykwinski, H. L. Anderson, J. Am. Chem. Soc. 2016, 138, 1366-1376; d) L. D. Movsisyan, D. V. Kondratuk, M. Franz, A. L. Thompson, R. R. Tykwinski, H. L. Anderson, Org. Lett. 2012, 14, 3424-3426; e) S. Schrettl, E. Contal, T. N. Hoheisel, M. Fritzsche, S. Balog, R. Szilluweit H. Frauenrath, Chem. Sci. 2015, 6, 564-574; f) Z. Baranová, H. Amini, N. Bhuvanesh, J. A. Gladysz, Organometallics 2014, 33, 6746-6749; g)

[4] a) A. Acevedo-Jake, A. T. Ball, M. Galli, M. Kukwikila, M. Denis, D. G. Singleton, A. Tavassoli, S. M. Goldup, J. Am. Chem. Soc. 2020, 142, 5985-5990; b) J. D. Crowley, S. M. Goldup, A.-L. Lee; D. A. Leigh, R. T. McBurney, Chem. Soc. Rev. 2009, 38, 1530-1541; c) O. Š. Miljanić, W. R. Dichtel, S. I. Khan, S. Mortezaei, J. R. Heath, J. F. Stoddart, J. Am. Chem. Soc. 2007, 129, 8236-8246; d) W. R. Dichtel, O. Š. Miljanić, J. M. Spruell, J. R. Heath, J. F. Stoddart, J. Am. Chem. Soc. 2006, 128, 10388-10390; e)

[5] a) K. Kaiser, L. M. Scriven, F. Schulz, P. Gawel, L. Gross, H. L. Anderson, Science 2019, 365, 1299-1301; b) Y.-Q. Zhang, N. Kepčija, M. Kleinschrodt, K. Diller, S. Fischer, A. C. Papageorgiou, F. Allegretti J. Björk, S. Klyatskaya, F. Klappenberger, M. Ruben, J. V. Barth, Nat. Commun. 2012, 3, 1286; c)

[6] a) M. Meldal, F. Diness, Trends Chem. 2020, 2, 569-584; b) M. Meldal, C. W. Tornøe, Chem. Rev. 2008, 108, 2952-3015; c) H. C. Kolb, M. G. Finn, K. B. Sharpless Angew. Chem. Int. Ed. 2001, 40, 2004-2021.

[7] P. R. Sruthi, S. Anas, J. Polym. Sci. 2020, 58, 1039-1061;

[8] a) Y. Wang, Y. Du, N. Huang, Future Med. Chem. 2018, 10, 2713 2728; b) F. F. Fleming, L. Yao; P. C. Ravikumar, L. Funk, B. C. Shook J. Med. Chem. 2010, 53, 7902-7917; c)

[9] H. Ju, H. Tenma, M. Iwase, E. Lee, M. Ikeda, S. Kuwahara, Y. Habata, Dalton Trans. 2020, 49, 3112-3119.

[10] P. Maity, S. Takano, S. Yamazoe, T. Wakabayashi, T. Tsukuda, J. Am. Chem. Soc. 2013, 135, 9450-9457.

[11] a) A. Holme, K. J. Børve, L. J. Sæthre, T. D. Thomas, J. Phys. Chem. A 2013, 117, 2007-2019; b) K. Shibasaki, A. Fujii, N. Mikami, S. Tsuzuki, J. Phys. Chem. A 2007, 111, 753-758; c) J. M. A. Robinson, D. Philp, B. M. Kariuki, K. D. M. Harris, Chem. Commun. 1996, 329-330.

[12] F. Maharaj, D. C. Craig, M. L. Scudder, R. Bishop, N. Kumar, J. Incl. Phenom. Macrocycl. Chem. 2007, 59, 17-24

[13] W. G. Klemperer, T. A. Marquart, O. M. Yaghi, Mat. Chem. Phys. 1991, 29, 97-104.

[14] J. Xu, Y. Yu, G. Li, S. Wang, Y. Liu, D. Liu, C. Wang, RSC Adv. 2016, 6, 104451-104455.

[15] a) M. K. Dhinakaran, W. Gong, Y. Yin, A. Wajahat, X. Kuang, L. Wang, G. Ning, Polym. Chem. 2017, 8, 5295-5302; b) Y. Zhou, K. Jie, B. Shi, Y. Yao, Chem. Commun. 2015, 51, 11112-11114.

[16] J. Radell, J. W. Connolly, L. D. Yuhas, J. Org. Chem. 1960, 26, 2022 2025.

[17] D. Ajami, J. Rebek, Jr. Heterocycles 2008, 76, 169-176.

[18] a) M. Kawahata, M. Tominaga, K. Fujimaru, T. Hyodo, K. Yamaguchi, Tetrahedron 2019, 75, 130576. See also: b) M. Tominaga, H. Masu, I. Azumaya, Cryst. Growth Des. 2011, 11, 542-546; c) M. Tominaga, H. Masu, I. Azumaya, CrystEngComm 2011, 13, 5299-5302; d) M Tominaga, K. Katagiri, I. Azumaya, Cryst. Growth Des. 2009, 9, 36923696.

[19] C. M. McHale, C. R. Stegemoller, M. I. Hashim, X. Wang, O. Š. Miljanić, Cryst. Growth Des. 2019, 19, 562-567.

[20] (a) M Alrayyani, O. Š. Miljanić, Chem. Commun. 2018, 54, 1198911997. (b) Q. Ji, H. T. M. Le, X. Wang, X. Y.-S. Chen, T. Makarenko, A J. Jacobson, O. Š. Miljanić, Chem. Eur. J. 2015, 21, 17205-17209. (c) Q. Ji, L. H. Do, O. Š. Miljanić, Synlett 2015, 26, 1625-1627.

[21] C. A. Hunter, J. K. M. Sanders, J. Am. Chem. Soc. 1990, 112, 55255534.

[22] It should be noted that the lowest energy calculated structure of $\mathbf{1 a \cdot 2}$ has the Me group of $\mathbf{2}$-and not its $\mathrm{CN}$ bond-included into the cavity of $1 \mathrm{a}$, with the shortest $[\mathrm{C}-\mathrm{H} \cdots \pi]$ distance of $2.62 \AA$.
[23] M. O. Sinnokrot, E. F. Valeev, C. D. Sherrill. J. Am. Chem. Soc. 2002 124, 10887-10893.

[24] Other effects can possibly beplaying a role in the observed packing patterns. They include the steric repulsion of the ortho-hydrogens in $\mathbf{6}$ and $\mathbf{7}$ and the macrocycles, as well as the effects of larger acyl groups appended to $\mathbf{1 b}$ and $\mathbf{1 c}$ on their co-crystal packing.

[25] A. M. Eisterhold, T. Puangsamlee, S. Otterbach, S. Bräse, P. Weis, X. Wang, K. V. Kutonova, O. Š. Miljanić, Org. Lett. 2021, doi 10.1021/acs.orglett.0c04014. 
